\title{
A VINCULAÇÃO DAS SÚMULAS E JURISPRUDÊNCIAS AOS CONTRATOS DE PLANO DE SAÚDE
}

Ademos Alves da Silva Júnior ${ }^{1}$ Romulo Almeida Carneiro ${ }^{2}$

SILVA JÚNIOR, A. A. da; CARNEIRO, R. A. A vinculação das súmulas e jurisprudências aos contratos de plano de saúde. Rev. Ciênc. Juríd. Soc. UNIPAR. Umuarama. v. 18, n. 1, p. 5-23, jan./jun. 2015.

RESUMO: O presente trabalho tem como objetivo demonstrar a vinculação das súmulas e decisões judiciais concernentes aos contratos de planos de saúde. Primeiramente fora desenvolvido tópico demonstrando a evolução histórica do direito à saúde, demonstrando ser um direito de segunda dimensão e frisando os principais marcos históricos. Em seguida, explicitou-se a estrutura da saúde brasileira, possuindo um Sistema Único de Saúde e um Sistema Suplementar privado, demonstrando-se os deveres de cada um. Para finalizar foi demonstrado que mesmo com toda a legislação elaborada para a proteção dos usuários dos planos de saúde, faz-se necessário a intervenção do Poder Judiciário em casos de excessos cometidos por estes, para assegurar o respeito à legislação.

PALAVRAS-CHAVE: Saúde; Planos de saúde; Segunda dimensão; Direitos fundamentais; Jurisprudência.

\section{INTRODUÇÃO}

Vislumbra-se atualmente que o Direito à saúde galga de um status de Direito fundamental, no entanto, para que se chegasse até este patamar houve duradoura luta.

Neste sentido a partir da evolução histórica denota-se as conquistas adquiridas, tanto no âmbito mundial, quanto no âmbito interno.

No Brasil, desde a Constituição de 1824, já haviam preocupações acerca do direito à saúde, ocorre que somente com a Constituição Federal de 1988 este direito foi consagrado e reconhecido como um direito social elevado a direito fundamental.

DOI: https://doi.org/10.25110/rcjs.v18i1.2015.5407

${ }^{1}$ Pós-graduado em Direito Processual pela Universidade da Amazônia; Mestrando em Direito Processual e Cidadania pela Universidade Paranaense, Professor do Centro Universitário da Grande Dourados - UNIGRAN e Advogado.

${ }^{2}$ Pós-graduado em Direito Processual Civil pela Universidade Gama Filho; Pós-graduado em Direito Tributário pelo Instituto Brasileiro de Estudos Tributários - IBET; Mestrando em Direito Processual e Cidadania pela Universidade Paranaense e Advogado. 
Após a promulgação da Constituição Federal de 1988, o legislador infraconstitucional produziu nos anos de 1990 importantes legislações voltadas à saúde, inclusive cria-se o Sistema Único de Saúde, a Lei dos Planos de Saúde Suplementar e a Agência Nacional de Saúde Suplementar.

Apesar de toda a produção e sistematização normativa construída, existe muito desrespeito em face dos usuários dos planos de saúde, obrigando a intensa atuação do Poder judiciário, o qual restou incumbido de resguardar os direitos destes.

\section{CONCEITO DE SAÚDE}

A palavra saúde advêm do latim (Salus-utis) que significa "estado-são" e "salvação".

O Dicionário Brasileiro Globo (1991), apresenta a seguinte definição para saúde: estado do que é são; estado do indivíduo em que há exercício regular das funções orgânicas; boa disposição do organismo; vigor; robustez.

Portanto, o direito à saúde seriam normas que proporcionam aos seres humanos proteção ao exercício das funções básicas de bem-estar, físico, mental e social.

\section{EVOLUÇÃO HISTÓRICA DO DIREITO À SAÚDE}

O direito à saúde é uma conquista extremamente relevante, sendo o resultado de muitos anos de luta, para então adquirir o status de um direito humano e fundamental.

Nesse sentido, esclarece Ingo Wolfgang Sarlet (2001, p 91):

A saúde comunga, na nossa ordem jurídica-constitucional, da dupla fundamentalidade formal e material da qual se revestem os direitos e garantias fundamentais em geral, especialmente em virtude de seu regime jurídico privilegiado.

Na idade média, período pelo qual a sociedade passou por terríveis dificuldades, pestes, epidemias e conflitos militares, o direito à saúde sofreu um grande retrocesso, as doenças eram tratadas como castigo divino, sendo impossível clamar pelo direito à saúde (SCHAFRANSK, 2003, p. 23).

Já no período do Renascimento, sendo marcado pela evolução no conhecimento humano, aconteceram avanços na área científica, sendo realizadas as primeiras descobertas acerca do corpo humano.

Com a consolidação do Estado Liberal Burguês, no século XVIII, e a 
Revolução Industrial, a obrigação de proporcionar à sociedade melhorias na área de saúde foram passadas ao Estado, sendo este incumbido de proporcionar e garantir a saúde pública. Tendo em vista da necessidade das indústrias em manter os seus operários saudáveis (SCHAFRANSK, 2003, p. 25).

Já no século XX houve o marco fundamental para a proteção da saúde, com a criação da Organização Mundial da Saúde, sendo essa uma agência especializada em saúde, subordinada às Nações Unidas.

Elucida Nayana Machado Freitas Rosa (2014) que a ideia inicial acerca de saúde era a de ausência de doenças, deficiências tratando-se de um conceito negativo, importando-se somente com as doenças do que a saúde propriamente dita.

Segundo Sérgio Pinto Martins (2005, p. 515), este entendimento do negativismo só foi rompido com a criação da Organização Mundial da Saúde, passando a vigorar uma concepção positivista e progressiva da saúde, considerado como um estado de completo bem-estar físico, mental e social, e não somente de ausência de doença.

Portanto, na medida da evolução histórica da sociedade, chega-se ao atual entendimento de que o direito à saúde é um direito subjetivo que deve ser exigido do Estado, o qual tem a obrigação de proporcionar aos indivíduos.

\subsection{DIREITO À SAÚDE - UM DIREITO DE SEGUNDA DIMENSÃO}

Sempre quando analisa-se um direito fundamental do homem, no caso em apreço, direito à saúde, faz-se mister compreender a evolução da consagração desses direito, haja vista a crescente preocupação adquirida com os anos.

As Dimensões dos direitos fundamentais, são na verdade os períodos demarcados na história de reconhecimento aos direitos fundamentais, nas palavras de Uadi Lammêgo Bulos (2007, p. 402) "Gerações dos direitos fundamentais são os períodos que demarcam a evolução das liberdades públicas.".

Diante da constante mutação histórica, a doutrina divide as Dimensões em três até cinco, as três primeiras dimensões (gerações) já foram discutidas no Supremo Tribunal Federal, nas palavras do Min. Celso de Mello:

Enquanto os direitos de primeira geração (direitos civis e políticos)que compreendem as liberdades clássicas, negativas ou formais realçam o princípio da liberdade e os direitos de segunda geração (direitos econômico, sociais e culturais) - que se identificam com as liberdades positivas, reais ou concretas - acentuam o princípio da igualdade, os direitos de terceira geração, que materializam poderes de titularidade coletiva atribuídos genericamente a todas as formações sociais, consagram o princípio da solidariedade e constituem um 
momento importante no processo de desenvolvimento, expansão e reconhecimento dos direitos humanos, caracterizados, enquanto calores fundamentais indisponíveis, pela nota de uma essencial inexauribilidade (STF, Pleno, MS 22.164/SP, Rel. Min. Celso de Mello, DJ, 1, de 17-11-1995, p. 39206).

Assim, os direitos de primeira dimensão são os direitos civis e políticos, o de segunda são direitos econômicos, sociais e culturais, e o de terceira são os de fraternidade e solidariedade. Além dessas dimensões citadas temos a quarta dimensão que versa sobre os direitos atinentes democracia, a informação e ao pluralismo.

Direitos de primeira dimensão ou geração, são aqueles surgidos do produto de pensamentos liberal-burguês do século XVIII, baseados na Declaração Universal dos Direitos Humanos, a qual proclama os "direitos civis e políticos" que formam a primeira dimensão dos direitos fundamentais.

Ocorre que com a industrialização, bem como os graves problemas sociais e econômicos, e a observância de que a consagração da liberdade e igualdade não trouxe efetivamente o seu gozo, o Estado proporcionou os direitos de segunda dimensão, dando ênfase aos direitos econômicos, sociais e culturais, no qual o direito à saúde se encontra.

Verifica-se que os direitos de segunda dimensão nascem ainda no século XIX, mas se afirmam no século XX, nascendo abraçado ao princípio da igualdade, não mais protegendo os direitos de apenas um indivíduo e sim resguardando os direitos de uma coletividade.

Dessa forma, o indivíduo passa a contar com o Estado para proteger a sua liberdade, cabendo agora a esta prestação materiais positivas de proteção, inicialmente as constituições deram a esses direitos aplicação mediata, tendo em vista primeiramente não serem interessantes ao Estado, por meio de legislação, no entanto após longos embates, tornou-se também de aplicação imediata como os direitos de primeira dimensão.

Esta nova dimensão caracteriza-se por ser o marco distintivo da evolução dos direitos fundamentais, tanto pelo cunho prestacional do Estado, bem como do direito positivo, inicia-se a mudança em sua atuação, deixando sua postura negativista, passando exercer um papel ativo na solução das dificuldades sociais. Nesta perspectiva o direito à saúde adquire o status de um direito fundamental.

Após serem assegurados os direitos de segunda dimensão, surgiram também os direitos de terceira dimensão, tendo como perspectiva os direitos difusos e coletivos à própria coletividade. Segundo Paulo Bonavides (2007, p. 572), direitos de quarta dimensão vêm para concretizar os direitos das dimensões anteriores, garantindo a cidadania e o porvir de todos os povos, sendo assim le- 
gítima e possível a globalização política.

\subsection{MARCOS HISTÓRICOS DO DIREITO FUNDAMENTAL À SAÚDE}

Somente no ano de 1948 foi dado a devida importância em particular ao direito à saúde no âmbito mundial, com a Declaração Universal dos Direitos $\mathrm{Hu}$ manos, a qual consubstanciou todos um crescente processo de universalização dos direitos humanos, tendo esta declaração obtido força vinculante em 1966, com a assinatura do Pacto dos Direitos Econômicos Sociais e Culturais.

No Brasil, desde a Constituição de 1824, já houve a preocupação em estabelecer normas jurídicas de proteção à saúde, no entanto, somente com a Constituição de 1988 que houve uma maior abrangência e preocupação em relação, elevando à saúde a um direito fundamental, tendo no ano de 1992 a ratificação do Pacto dos Direitos Econômicos, Sociais e Culturais.

Como corolário do direito à saúde como um direito social a Constituição Federal de 1988, estabelece no caput do art. 6, "São direitos sociais a educação, a saúde, a alimentação, o trabalho, a moradia, o lazer, a segurança, a previdência social, a proteção à maternidade e à infância, a assistência aos desamparados, na forma desta Constituição.”.

Fortalecendo a proteção do direito à saúde, o art. 23, inciso II, determina a competência comum entre União, Estados, do Distrito Federal e dos Municípios a atenção à Saúde, ou seja, os entes pertencentes ao Estado brasileiro tem solidariedade institucional no que tange à saúde.

E no art. 196 a Constituição Federal prevê:

Art. 196. A saúde é direito de todos e dever do Estado, garantido mediante políticas sociais e econômicas que visem à redução do risco de doença e de outros agravos e ao acesso universal e igualitário às ações e serviços para sua promoção, proteção e recuperação.

Sobre o tema leciona Uadi Lammêgo Bulos (2005, p.1339):

Da mesma forma que os direitos sociais em geral (art. $6^{\circ}$ ), o direito à saúde reclama, para sua efetivação, o cumprimento de prestações positivas e prestações negativas. Pela primeira, os Poderes Públicos devem tomar medidas preventivas ou paliativas ao combate e ao tratamento de doenças. Já pela segunda, incumbe a eles abster-se, deixando praticar atos obstaculizadores do cabal exercício desse direito fundamental.

Extrai-se do artigo acima colacionado, que o constituinte descreveu cor- 
retamente a função do Estado em face da saúde, lhe imputando grande importância para o bem-estar social.

Nesta toada, vislumbra-se do art. 198 da Constituição Federal no qual constam diretrizes às ações e aos serviços públicos de saúde, criando-se um Sistema Único de Saúde. Com base nisso, o legislador infraconstitucional criou a Lei Orgânica da Saúde, Lei n. 8.080/1990, a qual disciplina, promove e protege a saúde, disciplinando os serviços prestados, e a Lei 8.142/1990, que disciplina o papel da participação da comunidade na gestão do SUS.

Embora ainda tenhamos uma saúde pública precária, a criação do Sistema Único de Saúde, trouxe um grande avanço na saúde pública nacional e encontra-se ainda em desenvolvimento.

\section{DOS PLANOS DE SAÚDE SUPLEMENTAR}

Além do Sistema Único de Saúde implantado pela Constituição Federal de 1988, o qual é financiado pelo poder público, garantindo acesso universal em todos os níveis de atenção à saúde, no Brasil existem os planos suplementares de saúde.

O sistema suplementar de saúde consiste na contratação privada de um plano de saúde, esclarece Jussara Borges Ferreira e Kelly Cardoso Mendes de Moraes (2014, p. 116):

O Plano Privado de Assistência à Saúde constitui-se de prestação continuada de serviços ou cobertura de custos assistenciais a preço pré ou pós-estabelecido, por prazo indeterminado, com a finalidade de garantir, sem limite financeiro, a assistência à saúde, pela faculdade de acesso e atendimento por profissionais ou serviços de saúde, livremente escolhidos integrantes ou não de rede credenciada, contratada ou referenciada, visando à assistência médica, hospitalar e odontológica, a ser paga integral ou parcialmente, às expensas da operadora contratada, mediante reembolso ou pagamento direto ao prestador, por conta e ordem do consumidor.

A partir do momento em que um cidadão contrata um plano de saúde a ele deverá ser proporcionado sem limite financeiro a assistência à saúde, podendo optar pelo profissional de saúde que melhor atendê-lo, sendo este credenciado ou não ao plano.

O plano sistema de saúde suplementar funciona entre a combinação de entidades públicas e privadas, tendo um sistema universal, SUS e um sistema suplementar, o qual seria alternativa a este.

Como já mencionado em tópico anterior, com o advento da Constitui- 
ção Federal de 1988, houve uma mudança na atenção desferida à saúde, sendo incumbido o Estado o dever de garantir por meio de políticas sociais e econômicas a prevenção à doença e o seu atendimento universal e igualitário aos serviços de promoção, proteção e recuperação.

O art. 197 da Constituição Federal, in verbis:

Art. 197. São de relevância pública as ações e serviços de saúde, cabendo ao Poder Público dispor, nos termos da lei, sobre sua regulamentação, fiscalização e controle, devendo sua execução ser feita diretamente ou através de terceiros e, também, por pessoa física ou jurídica de direito privado.

Deverá ainda o Poder Público, regular, fiscalizar e controlar as ações e serviços de saúde, podendo ser executado diretamente ou por meio de terceiros. As ações e serviços de saúde são da competência integral do Poder Público. Tanto terceiros como pessoas físicas ou jurídicas de direito privado sujeitam-se ao seu domínio, nos termos da lei (BULOS, 2007, p. 1340).

Cumprindo com as normas constitucionais de eficácia limitada, o legislador infraconstitucional, instituiu a Lei n. 8.080/90, que dispõe sobre o SUS Sistema Único de Saúde, anteriormente já mencionada, e posteriormente a lei n. 9.656/98, a qual dispõe sobre os planos e seguros privados de assistência à saúde.

Posteriormente, tendo como base o Decreto n. 3.327/2000, e a medida provisória n. 2.012-2, de 30 de dezembro de 1999, foi criada a ANS - Agência Nacional de Saúde Suplementar, autarquia vinculada ao Ministério da Saúde, tendo como função a de órgão de regulação, normatização, controle e fiscalização das atividades que garantam a assistência suplementar de saúde.

\subsection{DOS CONTRATOS DE PLANO DE SAÚDE SUPLEMENTAR}

Os contratos de planos de saúde tiveram sua primeira referência no direito brasileiro no Decreto-lei n. 73/66, eram abarcados pelos contratos de seguros, após alterações advindas pelo Decreto-lei n. 296/67, foi instituído o seguro de saúde abrangendo coberturas à assistência médica e hospitalar, era administrado por uma Sociedade-Seguradora, o assegurado efetuava pagamento em dinheiro do prêmio àquela e em caso de sinistro e a necessidade da utilização do seguro, a seguradora repassaria esse valor ao prestador do serviço médico-hospitalar. (FERREIRA; MORAES, 2014, p. 115).

Hodiernamente, os contratos de planos de saúde suplementar devem seguir os preceitos determinados pela legislação, bem como pela Agência Nacional de Saúde Suplementar, tendo como característica serem: bilateral, oneroso, comutativo, consensual, nominado, não solene, principal e de adesão. 
Insta salientar que ainda existem contratos vigentes anteriores à lei $\mathrm{n}$. 9.656/98, os quais não estão abrangidos pela lei ante ao princípio da irretroatividade, no entanto, o usuário possui a faculdade de adaptar o seu plano às disposições da lei dos planos de saúde.

Os contratos de plano de saúde firmados após a entrada em vigor da lei n. 9.656/98, estão submetidos aos regramentos por ela previsto, bem como proporcionar aos usuários a cobertura assistencial definida pela Agência Nacional de Saúde relativas às doenças reconhecidas pela Organização Mundial de Saúde.

Acrescenta-se que após a edição da lei n. 9.656/98, os contratos de plano de saúde passaram a ser regidos pelos preceitos desta lei, ainda só podem ser oferecidos aos usuários após serem aprovados pela Agência Nacional de Saúde.

Embora tenha-se construído toda uma política de proteção à saúde após a promulgação da Constituição Federal, edição da Lei n. 8.080/90, 9.656/98 e criação da ANS - Agência Nacional de Saúde Suplementar, as operadoras de planos de saúde continuam cometendo abusos em relação aos usuários, obrigando a atuação do Poder Judiciário para solucionar os conflitos.

\section{DA VINCULAÇÃO DAS SÚMULAS E DOS PRECEDENTES AOS CONTRATOS DE PLANO DE SAÚDE}

Como acima já mencionado, apesar de toda a proteção existente à saúde, tanto pela própria Constituição Federal, quanto pela legislação infraconstitucional não foram capazes de frear os atos abusivos cometidos pelos planos de saúde.

Neste sentido, o Poder judiciário tem atuado em muitos casos referente aos contratos de planos de saúde, editando súmulas e construindo grande quantidade de jurisprudência.

\subsection{SÚMULAS SOBRE PLANO DE SAÚDE}

$\mathrm{Na}$ tentativa de proporcionar julgamento rápido, e a crescente demanda pelo amparo jurídico em questões litigiosas, tornou-se necessário a criação de alguns mecanismos para tornar mais ágil o julgamento dos processos, proporcionando segurança jurídica. Dentre esses mecanismos surgem as súmulas.

Súmulas são o resultado da uniformização do entendimento de um tribunal a respeito de determinada matéria, como dispõe o art. 479 do Código de Processo Civil, in verbis:

Art. 479. O julgamento, tomado pelo voto da maioria absoluta dos membros que integram o tribunal, será objeto de súmula e constituirá 
precedente na uniformização da jurisprudência.

Nesse sentido Lênio Streck (1998. p. 114-116) esclarece sobre súmula:

[...] o resultado da jurisprudência predominante de um tribunal superior brasileiro, autorizado pelo Código de Processo Civil. [...]proporcionar maior estabilidade à jurisprudência e simplificar o julgamento das questões mais freqüentes perante o Judiciário.

Portanto, súmulas seriam o resultado do entendimento pacificado a respeito de uma determinada matéria em um tribunal, sendo o precedente na uniformização da jurisprudência.

Devido ao grande número de demandas a respeito de plano de saúde em todo o território nacional, serão tratados apenas súmulas criadas pelo Superior Tribunal de Justiça.

No Superior Tribunal de Justiça existem duas principais súmulas aplicados aos contratos de plano de saúde, sendo elas:

Súmula 469: Aplica-se o Código de Defesa do Consumidor aos contratos de plano de saúde.

Essa súmula atene aos preceitos legais impostos pela lei 8.078/90 e 9.656/98, bem como ao entendimento consolidado do STJ, que assevera "[...] a operadora de serviços de assistência à saúde que presta serviços remunerados à população tem sua atividade regida pelo Código de Defesa do Consumidor, pouco importando o nome ou a natureza jurídica que adota"(Resp 267.530/SP, Rel. Ministro Ruy Rosado de Aguiar, DJe 12/3/2001).

Em outro julgado o Ministro Luis Felipe Salomão também já explicitou o entendimento:

Tratando-se de contrato de plano de saúde de particular, não há dúvidas de que a convenção e as alterações ora analisadas estão submetidas ao regramento do Código de Defesa do Consumidor, ainda que o acordo original tenha sido firmado anteriormente à entrada em vigor, em 1991, dessa lei. Isso ocorre não só pelo CDC ser norma de ordem pública (art. $5^{\circ}, \mathrm{XXXII}$, da CF), mas também pelo fato de o plano de assistência médico-hospitalar firmado pelo autor ser um contrato de trato sucessivo, que se renova a cada mensalidade (Resp 418.572/SP. Rel. Ministro Luis Felipe Salomão, DJe 30/3/2009).

Por conseguinte, a súmula 469 do STJ consolida o entendimento de que os contratos de planos de saúde são regidos pelo Código de Defesa do Consu- 
midor.

Outro entendimento que restou sumulado:

Súmula 302: É abusiva a cláusula contratual de plano de saúde que limita no tempo a internação hospitalar do segurado.

O posicionamento do Superior Tribunal de Justiça torna inválidas as cláusulas contratuais presentes em contratos de planos de saúde que limitem o tempo de internação do consumidor, tanto para os contratos anteriores a lei 9.656/98, quanto para os posteriores.

Esta súmula além de consolidar entendimento sobre a matéria, consubstancia a vulnerabilidade do consumidor, prevalecendo o princípio da boa-fé objetiva.

Vale destacar o julgado tendo como Relator o Ministro Sálvio Figueiredo:

DIREITO CIVIL E DO CONSUMIDOR. PLANO DE SAÚDE. LIMITAÇÃO TEMPORAL DE INTERNAÇÃO. CLÁUSULA ABUSIVA. CÓDIGO DE DEFESA DO CONSUMIDOR, ART. 51-IV. UNIFORMIZAÇÃO INTERPRETATIVA. PREQUESTIONAMENTO IMPLÍCITO. RECURSO CONHECIDO E PROVIDO. I - E abusiva, nos termos da lei (CDC, art. 51-IV), a cláusula prevista em contrato de seguro-saúde que limita o tempo de internação do segurado. II Tem-se por abusiva a cláusula, no caso, notadamente em face da impossibilidade de previsão do tempo da cura, da irrazoabilidade da suspensão do tratamento indispensável, da vedação de restringir-se em contrato direitos fundamentais e da regra de sobredireito, contida no art. $5^{\circ}$ da Lei de Introdução ao Código Civil, segundo a qual, na aplicação da lei, o juiz deve atender aos fins sociais a que ela se dirige a às exigências do bem comum. III Desde que a tese jurídica tenha sido apreciada e decidida, a circunstância de não ter constado do acórdão impugnado referência ao dispositivo legal não é obstáculo ao conhecimento do recurso especial (REsp: 251024 SP 2000/0023828-7, Relator: Ministro SÁLVIO DE FIGUEIREDO TEIXEIRA, Data de Julgamento: 27/09/2000).

Logo, ao verificarmos a existência de entendimentos sumulados pelo Superior Tribunal de Justiça, vislumbra-se que existe grande atuação do Poder Judiciário, vinculando às operadoras de Planos de Saúde ao seu entendimento, ocorre que além desses casos sumulados, existem outros que serão aborados no próximo tópico. 


\subsection{PRECEDENTES JURISPRUDENCIAIS - CONTRATOS DE PLANO DE SAÚDE}

Como já amplamente demonstrado, o Poder judiciário está constantemente influenciando a relação entre os planos de saúde e os consumidores, devido às abusividades por aqueles praticadas.

\subsubsection{LIMITAÇÃO DO VALOR DE TRATAMENTO}

O Superior Tribunal de Justiça já definiu a questão a respeito da limitação do tempo de internação, inclusive sumulou seu entendimento, Súmula 302.

No mesmo sentido, a Quarta Turma do Superior Tribunal de Justiça no julgamento do Recurso Especial n. 326.147, proferiu o julgado considerando também abusivo a limitação do valor de tratamento e de internações de seus associados. Ementa abaixo:

CIVIL E PROCESSUAL. ACÓRDÃO ESTADUAL. OMISSÕES NÃO CONFIGURADAS. SEGURO-SAÚDE. CLÁUSULA LIMITATIVA DE VALOR DE DESPESAS ANUAIS. ABUSIVIDADE. ESVAZIAMENTO DA FINALIDADE DO CONTRATO. NULIDADE. I. Não padece do vício da omissão o acórdão estadual que enfrenta suficientemente as questões relevantes suscitadas, apenas que trazendo conclusões adversas à parte irresignada. II. A finalidade essencial do seguro-saúde reside em proporcionar adequados meios de recuperação ao segurado, sob pena de esvaziamento da sua própria ratio, o que não se coaduna com a presença de cláusula limitativa do valor indenizatório de tratamento que as instâncias ordinárias consideraram coberto pelo contrato. III. Recurso especial conhecido e provido (RESp n. 326.147, Rel. Ministro ALDIR PASSARINHO JUNIOR, Data de Julgamento: 21/05/2009).

A restrição quanto ao valor de custeio do tratamento do mesmo modo esvazia o propósito do contrato, o qual é assegurar ao paciente meios para sua cura, portanto, foi considerada abusiva a conduta do plano de saúde, alinhando-se ao entendimento já sumulado.

\subsubsection{REAJUSTES}

Outro grande debate judicial existente no Superior Tribunal de Justiça são as abusividades cometidas pelos planos de saúde nos reajustes dos valores, com ênfase quando há mudança da faixa etária do assegurado. 
A Terceira Turma já decidiu ao julgar o Recurso Especial n. 989.380, vedando os reajustes nas mensalidades dos planos de saúde em razão de faixa etária daqueles que completassem a idade de 60 anos ou mais, ficando a operadora obrigada a praticar o reajuste aos idosos nos mesmos percentuais praticados com os demais usuários.

Ementa abaixo:

Direito civil e processual civil. Estatuto do Idoso. Planos de Saúde. Reajuste de mensalidades em razão de mudança de faixa etária. Vedação. - O plano de assistência à saúde é contrato de trato sucessivo, por prazo indeterminado, a envolver transferência onerosa de riscos, que possam afetar futuramente a saúde do consumidor e seus dependentes, mediante a prestação de serviços de assistência médico-ambulatorial e hospitalar, diretamente ou por meio de rede credenciada, ou ainda pelo simples reembolso das despesas. - Como característica principal, sobressai o fato de envolver execução periódica ou continuada, por se tratar de contrato de fazer de longa duração, que se prolonga no tempo; os direitos e obrigações dele decorrentes são exercidos por tempo indeterminado e sucessivamente. - Ao firmar contrato de plano de saúde, o consumidor tem como objetivo primordial a garantia de que, no futuro, quando ele e sua família necessitarem, obterá a cobertura nos termos em contratada. - $\mathrm{O}$ interesse social que subjaz do Estatuto do Idoso, exige sua incidência aos contratos de trato sucessivo, assim considerados os planos de saúde, ainda que firmados anteriormente à vigência do Estatuto Protetivo. - Deve ser declarada a abusividade e conseqüente nulidade de cláusula contratual que prevê reajuste de mensalidade de plano de saúde calcada exclusivamente na mudança de faixa etária de 60 e 70 anos respectivamente, no percentual de $100 \%$ e $200 \%$, ambas inseridas no âmbito de proteção do Estatuto do Idoso. - Veda-se a discriminação do idoso em razão da idade, nos termos do art. $15, \S 3^{\circ}$, do Estatuto do Idoso, o que impede especificamente o reajuste das mensalidades dos planos de saúde que se derem por mudança de faixa etária; tal vedação não envolve, portanto, os demais reajustes permitidos em lei, os quais ficam garantidos às empresas prestadoras de planos de saúde, sempre ressalvada a abusividade. Recurso especial conhecido e provido (REsp n. 989.380, Relator: Ministra NANCY ANDRIGHI, Data de Julgamento: 06/11/2008).

Pelo entendimento desenvolvido pela ministra Relatora Nancy Andrighi, ao completar a idade de 60 anos, o idoso estará sempre amparado contra a abusividade de reajustes das mensalidades do plano de saúde baseados exclusivamente na mudança de faixa etária, por força da proteção consumerista, bem como promovida pelo Estatuto do Idoso. 


\subsubsection{COBERTURA DO PLANO DE SAÚDE}

Cobertura do plano de saúde é o conjunto de direito que o consumidor adquire ao contratar o plano de saúde, e a extensão da cobertura deve estar expressamente prevista no contrato do plano de saúde. No entanto, este tema vem sendo constantemente tratado no Superior Tribunal de Justiça.

A Terceira Turma já decidiu ser devido a cobertura de cirurgia plástica para retirada do excesso de pele em decorrência a cirurgia bariátrica, sustentando que tal procedimento faz parte do tratamento à obesidade mórbida, ementa:

RECURSO ESPECIAL - AÇÃO ORDINÁRIA - PLANO DE SAÚDE - PRELIMINAR - INFRINGÊNCIA AO PRINCÍPIO DA IDENTIDADE FÍSICA DO JUIZ - NÃO VERIFICAÇÃO, NA ESPÉCIE - MÉRITO - CIRURGIA DE REMOÇÃO DE TECIDO EPITELIAL APÓS A SUBMISSÃO DA PACIENTE-SEGURADA À CIRURGIA BARIÁTRICA - PROCEDIMENTO NECESSÁRIO E COMPLEMENTAR AO TRATAMENTO DA OBESIDADE, ESTE INCONTROVERSAMENTE ABRANGIDO PELO PLANO DE SAÚDE CONTRATADO, INCLUSIVE, POR DETERMINAÇÃO LEGAL - ALEGAÇÃO DE FINALIDADE ESTÉTICA DE TAL PROCEDIMENTO - AFASTAMENTO - NECESSIDADE - COBERTURA AO TRATAMENTO INTEGRAL DA OBESIDADE - PRESERVAÇÃO DA FINALIDADE CONTRATUAL - NECESSIDADE - RECURSO ESPECIAL IMPROVIDO. I - No caso dos autos, a magistrada que concluiu a audiência de instrução e julgamento afastou-se do feito para assumir a titularidade de outra Vara e exercer a jurisdição em outra Comarca, hipótese que se enquadra na cláusula genérica pré-citada: "afastamento por qualquer motivo", na esteira da jurisprudência desta Corte; II - Encontrando-se o tratamento da obesidade mórbida coberto pelo plano de saúde entabulado entre as partes, a seguradora deve arcar com todos os tratamentos destinados à cura de tal patologia, o principal - cirurgia bariátrica (ou outra que se fizer pertinente) - e os subseqüentes ou conseqüentes - cirurgias destinas à retirada de excesso de tecido epitelial, que, nos termos assentados, na hipótese dos autos, não possuem natureza estética; III - As cirurgias de remoção de excesso de pelé (retirada do avental abdominal, mamoplastia redutora e a dermolipoctomia braçal) consiste no tratamento indicado contra infecções e manifestações propensas a ocorrer nas regiões onde a pelé dobra sobre si mesma, o que afasta, inequivocamente, a tese sufragada pela parte ora recorrente no sentido de que tais cirurgias possuem finalidade estética; IV - Considera-se, assim, ilegítima a recusa de cobertura das cirurgias destinadas à remoção de tecido epitelial, quando estas se revelarem necessárias ao pleno resta- 
belecimento do paciente-segurado, acometido de obesidade mórbida, doença expressamente acobertado pelo plano de saúde contratado, sob pena de frustrar a finalidade precípua de tais contrato; V - Recurso Especial improvido (REsp 1.136.475. STJ. Relator: Ministro MASSAMI UYEDA, Data de Julgamento: 04/03/2010).

Neste caso o entendimento dos ministros foi de que não se tratava de uma cirurgia estética, e sim a decorrência de um tratamento à obesidade, ficando excluído do previsto no art. 10, inciso IV, da lei 8.656/983.

\subsubsection{INDENIZAÇÕES DEVIDAS PELAS OPERADORAS DE PLANOS DE SAÚDE}

Outras demandas que se discutem no âmbito do Superior Tribunal de Justiça são as indenizações materiais e de danos morais devidas pelos planos de saúde.

Muitas das vezes, os planos de saúde negam-se a cobrir as despesas de tratamento de seus usuários os obrigando a postular em juízo a reparação material, ocorre que o Superior Tribunal de Justiça vem entendendo ser devido dano moral ante a tal atitude:

AGRAVO REGIMENTAL EM AGRAVO (ART. 544 DO CPC) PLANO DE SAÚDE - RECUSA IMOTIVADA DE TRATAMENTO MÉDICO - DECISÃO MONOCRÁTICA CONHECENDO DO RECLAMO PARA DAR PARCIAL PROVIMENTO AO APELO ESPECIAL. INSURGÊNCIA DA ADMINISTRADORA DO PLANO DE SAÚDE. 1. A jurisprudência desta Corte é no sentido de que a recusa indevida/injustificada, pela operadora de plano de saúde, em autorizar a cobertura financeira de tratamento médico, a que esteja legal ou contratualmente obrigada, enseja reparação a título de dano moral, por agravar a situação de aflição psicológica e de angústia no espírito do beneficiário. Precedentes. 2. Agravo regimental desprovido. (AgRg no AREsp n. 7.386RJ, Relator o Ministro Marco Buzzi, DJe de 11/9/2012.)

AGRAVO REGIMENTAL. PLANO DE SAÚDE. PROCEDIMENTO CIRÚRGICO. RECUSA DA COBERTURA. INDENIZAÇÃO

\footnotetext{
${ }^{3}$ Art. 10. É instituído o plano-referência de assistência à saúde, com cobertura assistencial médico-ambulatorial e hospitalar, compreendendo partos e tratamentos, realizados exclusivamente no Brasil, com padrão de enfermaria, centro de terapia intensiva, ou similar, quando necessária a internação hospitalar, das doenças listadas na Classificação Estatística Internacional de Doenças e Problemas Relacionados com a Saúde, da Organização Mundial de Saúde, respeitadas as exigências mínimas estabelecidas no art. 12 desta Lei, exceto: [...]

IV - tratamento de rejuvenescimento ou de emagrecimento com finalidade estética;
} 
POR DANO MORAL. CABIMENTO. I - Em determinadas situações, a recusa à cobertura médica pode ensejar reparação a título de dano moral, por revelar comportamento abusivo por parte da operadora do plano de saúde que extrapola o simples descumprimento de cláusula contratual ou a esfera do mero aborrecimento, agravando a situação de aflição psicológica e de angústia no espírito do segurado, já combalido pela própria doença. Precedentes. II - Em casos que tais, o comportamento abusivo por parte da operadora do plano de saúde se caracteriza pela injusta recusa, não sendo determinante se esta ocorreu antes ou depois da realização da cirurgia, embora tal fato possa ser considerado na análise das circunstâncias objetivas e subjetivas que determinam a fixação do quantum reparatório. III - Agravo Regimental improvido (AgRg no Ag n. 884.832/RJ, Relator o Ministro Sidnei Beneti, DJe de 9/11/2010).

As recusas injustificadas para cobrir as despesas de tratamento de saúde, além de serem condenadas a arcar com as despesas materiais, os planos de saúde têm sido condenados à reparação por danos morais.

\subsubsection{DIREITO DE PERMANÊNCIA EM PLANO COLETIVO DE SAÚ- DE}

Outra discussão trazida ao Superior Tribunal de Justiça é a possibilidade do funcionário permanecer vinculado ao plano de saúde coletivo fornecido pela empresa.

O entendimento do STJ no REsp n. 1.078.991, foi de que o funcionário só poderá manter as mesmas vantagens usufruídas do plano de saúde coletivo, se for demitido ou exonerado sem justa causa, e o funcionário passe a arcar com as parcelas do plano. Ementa abaixo:

RECURSO ESPECIAL - AÇÃO DE OBRIGAÇÃO DE FAZER - PLANO DE SAÚDE EM GRUPO - CAIXA DE ASSISTÊNCIA DOS FUNCIONÁRIOS DO BANCO DO BRASIL (CASSI) - ARTIGO 30, CAPUT, DA LEI N. 9656/98 - NORMAAUTO-APLICÁVEL - PRECEDENTE - EX-EMPREGADO QUE PEDIU DEMISSÃO - PERMANÊNCIA NA QUALIDADE DE BENEFICIÁRIO - IMPOSSIBILIDADE - RESTRIÇÃO DA APLICAÇÃO DO ARTIGO 30, CAPUT, DA LEI N. 9656/98 - - LIMITAÇÃO TEMPORAL NA CONDIÇÃO DE BENEFICIÁRIO - NECESSIDADE - ARTIGO 30, $\S 1^{\circ}$, DA LEI N. 9656/98 - RECURSO ESPECIAL CONHECIDO E PROVIDO. 1. A norma inserta no artigo 30, caput, da Lei n. 9656/98 é auto-aplicável, bastando, pois, que o ex-empregado postule o exercício do direito de permanecer vinculado ao plano ou seguro privado 
coletivo de assistência à saúde. Precedente. 2. O direito de manter a condição como beneficiário, nas mesmas condições que gozava quando da vigência do contrato de trabalho, somente está previsto para os casos em que o empregado é demitido/exonerado sem justa causa. No caso em questão, o empregado pediu demissão. 3. O $\S 1^{\circ}$, do art. 30, da Lei 9.656/98 estabelece prazo mínimo de 6 (seis) meses e máximo de 24 (vinte e quatro) meses para a permanência do empregado exonerado/demitido sem justa causa permanecer no plano ou seguro saúde ao qual estava ligado durante período em que mantinha o vínculo empregatício. A prorrogação compulsória da permanência por tempo superior ao prazo máximo de 24 (vinte e quatro) meses, não encontra amparo legal. 4. A única hipótese legal de alteração no prazo do benefício do caput do art. 30, da Lei 9.656/98 é a estabelecida em seu $\S$ $5^{\circ}$, o qual prevê a sua extinção quando da admissão do ex-empregado em novo emprego. 6. Recurso especial conhecido e provido. (REsp n. 1.078.991 STJ, Relator: Ministro MASSAMI UYEDA, Data de Julgamento: 02/06/2009).

Decisão em consonância com o previsto na lei n. $9.656 / 1998$, no $\S 1^{\circ}$ do artigo $30^{4}$, mesmo com previsão legal expressa, a operadora do plano de saúde acaba não respeitando o direito de seu usuário.

\section{CONCLUSÃO}

Constata-se que para o reconhecimento do direito à saúde foi um longo período de luta e conquista até ser reconhecido como um direito fundamental.

No âmbito mundial teve como principal marco histórico a Declaração Universal dos Direitos Humanos em 1948 e no Brasil, apesar de a Constituição de 1824 já se preocupar com a elaboração de legislação em prol a saúde, somente com a Constituição Federal de 1988 houve o reconhecimento do direito à saúde como um direito social, galgando o status de direito fundamental.

A partir de 1988, houve uma construção normativa estruturada fundando-se o Sistema Único de Saúde e a regulamentação dos Planos de Saúde Suplementares, inclusive com criação de autarquia específica, Agência Nacional de Saúde Suplementar - ANS.

\footnotetext{
${ }^{4}$ Art. 30. Ao consumidor que contribuir para produtos de que tratam o inciso I e o $\S 1$ o do art. $1^{\circ}$ desta Lei, em decorrência de vínculo empregatício, no caso de rescisão ou exoneração do contrato de trabalho sem justa causa, é assegurado o direito de manter sua condição de beneficiário, nas mesmas condições de cobertura assistencial de que gozava quando da vigência do contrato de trabalho, desde que assuma o seu pagamento integral.

$\S 1$ O O período de manutenção da condição de beneficiário a que se refere o caput será de um terço

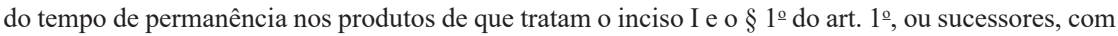
um mínimo assegurado de seis meses e um máximo de vinte e quatro meses.
} 
Apensar de existir ampla produção normativa para a proteção dos consumidores em face dos planos de saúde suplementares, estes acabam não respeitando os direitos, obrigando a intensa atuação do Poder Judiciário.

O Superior Tribunal de Justiça já possui súmulas e decisões consolidadas para soluções de casos concretos, tendo uma grande importância para resguardar e materializar o direito à saúde.

\section{REFERÊNCIAS}

BRASIL. Superior Tribunal de Justiça. Recurso especial no 267.530-SP. Relator Ruy Rosado de Aguiar. J. 14 dez 2000. Diário Oficial [da] República Federativa do Brasil, Brasília, 12 mar. 2001.

. Recurso especial no 418.572- SP. Relator Ministro Luis Felipe Salomão. J. 10 mar 2009. Diário da Justiça [da] República Federativa do Brasil, Brasília 30 de março de 2009.

. Recurso especial no 251.024- SP. Relator Ministro Sálvio de Figueiredo Teixeira. J. 27 set 2000. Diário da Justiça [da] República Federativa do Brasil, Brasília 04 fev. 2002.

. Recurso Especial no 326.147. Relator Ministro Aldir

Passarinho Junior. J. 21 maio 2009. Diário da Justiça [da] República Federativa do Brasil, Brasília, 08 jun. 2009.

. Recurso especial no 989. 380 - RN. Relator Ministro Nancy Andrighi. J. 06 nov. 2008. Diário [da] Justiça [da] República Federativa do Brasil, Brasília, 20 nov. 2008.

. Recurso especial no 1.136.475-RS. Relator Ministro Massami Uyeda. J. 04 mar. 2010. Diário [da] Justiça [da] República Federativa do Brasil, Brasília, 16 mar. 2010.

. Agravo regimental no recurso especial no 7.386-RJ.Relator Ministro Marco Buzzi. J. 04 set. 2012. Diário [da] Justiça [da] República Federativa do Brasil, Brasília, 11 set. 2012.

. Agravo regimental no agravo no 884.832-RJ. Relator Ministro Sidnei Beneti. J. 06 nov. 2010. Diário [da] Justiça [da] República Federativa do Brasil, Brasília, 09 nov. 2010. 
BONAVIDES, Paulo. Curso de direito constitucional. 19. ed. São Paulo: Malheiros, 2007.

BULOS, Uadi Lammêgo. Constituição Federal Anotada. 6. ed. São Paulo: Saraiva, 2005.

Curso de direito constitucional. São Paulo: Saraiva, 2007.

FERNANDO, Francisco; GUIMARÃES, F. Marques; LUFT, Celso Pedro. Dicionário brasileiro Globo. 21. ed. São Paulo: Globo,1991.

FERREIRA, Jussara Borges; MORAES, Kelly Cardoso Mendes. Contratos bancários e de planos de saúde: aplicabilidade do incidente de demandas repetitivas. Belo Horizonte: Arraes, 2014.

MARTINS, Sérgio Pinto. Direito da seguridade social. São Paulo: Atlas, 2005.

ROSA, Nayana Machado Freitas. Evolução histórica do direito à saúde face à atuação estatal e sua positivação no ordenamento jurídico brasileiro. Conteúdo Jurídico, Brasília, 27 nov. 2014. Disponível em: <http://www.conteudojuridico. com.br/?artigos\&ver=2.50997\&seo=1>. Acesso em: 04 abr. 2015.

SARLET, Ingo Wolfgang. Algumas considerações em torno do conteúdo, eficácia e efetividade do direito à saúde na Constituição de 1998. Revista Interesse Público, Porto Alegre, 2001.

SCHAFRANSKI, Sílvia Maria Derbli. Direitos humanos \& seu processo de universalização: análise da convenção americana. Curitiba: Juruá, 2003.

STRECK, Lenio Luiz. Súmulas no direito brasileiro: eficácia, poder e função. Porto Alegre: Livraria do Advogado, 1998, p. 114-116.

\title{
THE BINDING OF PRECEDENTS AND JURISPRUDENCE TO HEALTH PLAN AGREEMENTS
}

\begin{abstract}
This work aims to demonstrate the binding of precedents and court decisions pertaining to health insurance agreements. First, the theme was developed demonstrating the historical evolution of the right to health, proving to be a right of second dimension, emphasizing the major landmarks. Then, the Brazilian health structure was explained, since it has a Unified Health System
\end{abstract}


and a private Supplementary System, showing the responsibilities of each one. Finally, the paper shows that even with all legislation developed to protect the users of health plans, the intervention of the Judicial Power is necessary in cases of excesses committed by such plans, in order to guarantee the respect for the legislation.

KEYWORDS: Health; Health plans; Second dimension; Fundamental rights; Jurisprudence.

\section{LA VINCULACIÓN DE LAS SÚMULAS Y JURISPRUDENCIAS A LOS CONTRACTOS DE PLAN DE SALUD}

RESUMEN: Esta investigación ha tenido como objetivo demostrar la vinculación de las súmulas y decisiones judiciales concernientes a los contractos de planes de salud. En primer lugar fuera desarrollado tópico demostrando la evolución histórica del derecho a la salud, demostrando ser un derecho de segunda dimensión y destacando los principales hitos históricos. Enseguida, se explica la estructura de la salud brasileña, que tiene un Sistema Único de Salud y un Sistema Suplementar Privado, demostrándose los deberes de cada uno. Finalmente se ha demostrado que mismo con toda la legislación elaborada para la protección de los usuarios de los planes de salud, se hace necesaria la intervención del Poder Judiciario en casos de excesos cometidos por ellos, para asegurar el respeto a la legislación.

PALABRAS CLAVE: Salud; Planes de Salud; Segunda dimensión; Derechos fundamentales; Jurisprudencia. 